Elsevier

HRR 00883

\title{
Comparison of isolated outer hair cells from five mammalian species
}

\author{
Gary Zajic and Jochen Schacht \\ Kresge Hearing Research Institute, University of Michigan, Ann Arbor, MI 48109, U.S.A.
}

(Received 13 July 1986; accepted 2 November 1986)

\begin{abstract}
Live outer hair cells were isolated from guinea pig, chinchilla, rat, mouse, and gerbil. The organ of Corti from selected turns of the cochlea was briefly incubated with collagenase and outer hair cells were separated from the tissue by micromanipulation under microscopic observation. Morphological criteria for cell viability were: (1) cylindrical cell shape without swelling or distortion of the membrane; (2) location of the nucleus in its normal position near the base of the cell; (3) cytoplasm devoid of Brownian motion and granulation. Both yield and quality (as judged by these morphological criteria) of isolated hair cells varied with the species and the turn from which the isolation was attempted. Consistently high yields and cells of good morphology were obtained from guinea pigs and chinchillas. Fewer cells were obtained from rats and mice, and their quality was less consistent. Gerbils gave the poorest yield and quality of outer hair cells. In all species, the preparation was more successful from the apical than from the basal turn. The length of apical hair cells varied almost 4-fold from 60 to $80 \mu \mathrm{m}$ in guinea pig and chinchilla to 20 to $40 \mu \mathrm{m}$ in the other species, while their diameter only varied 1.5 -fold from 7 (mouse) to $10 \mu \mathrm{m}$ (chinchilla). Outer hair cells could be maintained in vitro in good condition for several hours. Typical early signs of degeneration were increased Brownian motion and granulation in the cytoplasm, upward movement of the nucleus, or distortion of cell shape. Degeneration was always accompanied by a shortening along the long axis.
\end{abstract}

Hair cell, outer; Isolated cell; Species difference; Morphology

\section{Introduction}

In recent years new theoretical concepts have emerged for the function of inner and outer hair cells of the mammalian cochlea. While the inner hair cells are considered primarily to be engaged in mechano-transduction, it has been postulated that the outer hair cells modify the micromechanics of the cochlea (Neely and Kim, 1986). In this context, the study of single outer hair cells in vitro has received renewed attention following the observation that isolated outer hair cells have motile properties (Brownell, 1984; Brownell et al., 1985; Zenner et al., 1985b).

Katsuki and Covell (1953) first isolated hair cells from the unfixed organ of Corti of the guinea pig and described their appearance in vitro. Goldstein and Mizukoshi (1967) increased the yield of cells using proteolytic digestion and observed $\mathrm{K}^{+}$induced contractions later confirmed by Zenner et

Correspondence address: J. Schacht, Kresge Hearing Research Institute, University of Michigan, Ann Arbor, MI 48109, U.S.A. al. (1985b). Thalmann et al. (1972) in a series of quantitative analytical studies of the organ of Corti measured cell dimensions of outer hair cells isolated from defined rows of the apical turn. Coinciding with the recent interest in the physiology of mammalian outer hair cells was the development of more convenient and more consistent procedures for their isolation (Brownell et al., 1985; Zenner et al., 1985b). Biochemical, pharmacological, physiological, immunological and morphological investigations will profit from this preparation which provides access to the sensory cells without interference by supporting structures and thus a direct approach to complex questions of cochlear physiology.

Although some of the previous studies described features of apparently intact or degenerating isolated hair cells, there is still a need to establish well-defined criteria for judging the viability of the cells in vitro. Morphology and biophysical characteristics of hair cells in the different reports vary considerably. Furthermore, while auditory research routinely employs a variety of 
mammalian species, hair cells have been isolated only from guinea pig (all studies cited above) and chinchilla (Lim and Flock, 1985). We have already studied the ototoxicity of aminoglycosides (Zenner and Schacht, 1986) and the biochemistry of motility (Schacht and Zenner, 1986) in outer hair cells of the guinea pig in vitro. The present study compares the yield and morphology of outer hair cells isolated from guinea pig, chinchilla, rat, mouse, and gerbil.

\section{Materials and Methods}

The animals for these experiments were of a young adult age. Pigmented guinea pigs (150-180 g) were obtained from Murphy Laboratories (Plainfield, IN), rats (Sprague-Dawley, 50-75 g) and mice (Balb/c, 15-20 g) from Charles River (Wilmington, MA), gerbils (approximately $50 \mathrm{~g}$ ) from Tumblebrook (West Bloomfield, MA), and chinchillas (360-460 g) from a local breeder (Ortenville, MI). Hank's balanced salt solution (HBSS) and Leibovitz L-15 tissue culture media were purchased from Gibco (Chagrin Falls, $\mathrm{OH}$ ) and collagenase (Type IV) from Sigma (St. Louis, MO). The osmolality of the culture media was measured in an Osmette A automatic osmometer (Precision Systems, Natick, MA) and adjusted to 300 mOsm with $\mathrm{NaCl}$. Hair cells were visualized during dissociation with a Leitz Labovert inverted microscope and studied with a Leitz Dialux 22 microscope equipped with differential interference contrast optics.

The isolation procedure was essentially the same as described by Zenner et al. (1985a, b). The animal was decapitated, the bulla and the otic capsule opened and the apical or other selected turn of the cochlea immediately removed and transferred into a drop of HBSS or Leibovitz medium in a $60 \times 15 \mathrm{~mm}$ Petri dish (Falcon 3002; Becton-Dickinson, Oxnard, CA). The organ of Corti was incubated in this medium with collagenase $(1 \mathrm{mg} / \mathrm{ml})$ for $10 \mathrm{~min}$ at room temperature, and subsequently placed into fresh HBSS. The hair cells were then manually teased from the basilar membrane with fine tungsten wire microprobes. After isolation, the cells were transferred onto a number 0 coverslip for further observation and photography.

\section{Results and Discussion}

\section{Yield of isolated cells}

Isolated hair cells were obtained from each of the species examined, although with variable yields (Table I). The yield from guinea pig and chinchilla was approximately the same as reported previously by others. From the apical turn about 200 individual cells could be obtained. Clusters of hair cells attached only by portions of Deiters' cells at the base accounted for an additional 200-300 cells. During the preparation, isolated supporting cells could be found and large numbers of phalangeal processes of Deiters' cells. Inner hair cells were rarely seen.

The yield of outer hair cells from mouse, rat and gerbil was considerably lower. When the lateral wall tissues were removed and the Hensen cells teased apart, large groups of supporting cells, pillar cells and phalangeal processes of Deiters' cells were frequently seen without attached hair cells. Occasionally, outer hair cells had been broken free from the surrounding tissue. Mostly, however, they seemed to clump together, and attempts to disperse or separate them were less successful than in guinea pig or chinchilla.

In all species the yield from the apical turn of

TABLE I

YIELD AND QUALITY OF ISOLATED OUTER HAIR CELLS

\begin{tabular}{llll} 
Species & Turn & Yield & Quality \\
\hline Guinea pig & $\begin{array}{l}\text { apex } \\
\text { base }\end{array}$ & ++ & ++ \\
Chinchilla & $\begin{array}{l}\text { apex } \\
\text { base }\end{array}$ & ++ & + \\
& $\begin{array}{l}\text { apex } \\
\text { base }\end{array}$ & \pm & ++ \\
Rat & apex & \pm & + \\
& base & - & + \\
Mouse & apex & - & - \\
& base & - & - \\
Gerbil & & & -
\end{tabular}

Yield: $t+$, consistently greater than 200 cells per preparation; + , less than 100 cells per preparation; - , poor.

Quality: ++ , cells consistently meet morphological criteria of viability; + , cells meet the criteria but are obtained with less consistency; - , difficult to obtain cells that meet the criteria. 
the cochlea was greater than from the base. This may be due to the decreased width and increased relative thickness of the basilar membrane toward the base of the cochlea and possible differences in the physical attachment of the hair cells.

Occasional observations suggested that the age of the animal affected the yield. In older animals (guinea pigs of $>500 \mathrm{~g}$ ) the reticular lamina seemed more resistant to the dissociation procedure and the isolation of outer hair cells became more difficult. However, this impression of an age-dependent change in the reticular lamina needs further study.

In rat and mouse the quality of the isolated cells was less consistent but cells satisfying the criteria of morphological integrity could be isolated. The cytoplasm (Figs. 3 and 5) is relatively clear and mitochondria and the nucleus are located in their normal positions. We were unable, however, to obtain hair cells from the gerbil that met the criteria. The cell in Fig. 4 is a typical example. The cylindrical shape of the cell and the low position of the nucleus are maintained and the cell membrane is not distorted nor are there any surface protrusions. However, the entire cytoplasm has a rough granular appearance. This may be the sign of an already ongoing degeneration although it cannot be ruled out that gerbil hair cells differ morphologically from those of other species.

The reasons for the variability of yield and quality are not obvious. Although no attempt was made to optimize the isolation of cells for each of the different species, some conditions of the procedure were varied. For example, the incubation time in collagenase was changed from $0 \mathrm{~min}$ (no collagenase treatment) to $10 \mathrm{~min}$ and osmolarity adjusted to range from 285 to 315 mOsm. Neither treatment brought any improvement. It remains possible that different essential nutrients are required for the maintenance of cells of these species, that they are more sensitive to the trauma of isolation or that different digestive enzymes might have improved the yield. However, Zenner et al. $(1985 \mathrm{a}, \mathrm{b})$ tested various enzymatic treatments on the guinea pig cochlea and reported detrimental effects of enzymes other than collagenase, an observation in agreement with the studies by Goldstein and Mizukoshi (1967), who noted that pro- longed treatment with proteolytic enzymes destroyed hair cells. This does not preclude the isolation of viable cells by other procedures (Brownell, 1984) but it needs to be considered that proteolytic enzymes are rather aggressive. They not only aid in separating cells, they also attack cell surface proteins. Such cells may show normal morphology but may have lost for example, recognition molecules at receptor sites or immunologically important surface antigens. Enzymatic treatment may, therefore, not only be detrimental but for certain studies also not desirable. At least in the guinea pig, we were able to isolate outer hair cells without prior enzymatic treatment albeit at lower yield.

\section{Morphology}

In order for an isolated outer hair cell to be considered of good morphological quality it had to meet the following criteria: (1) the cell must have a cylindrical shape; (2) there must be no swelling or other distortion of the cell membrane; (3) the nucleus must not be displaced from its normal position near the base of the cell; (4) there must be no visible extrusion of cytosol from the cell; and (5) there must be no Brownian motion of the organelles within the cytoplasm. These criteria were based on published morphological studies of fixed 'normal' hair cells, on the early reports of isolated hair cells, and on our observations of the best cells obtained and their morphological changes with time.

The quality of the hair cells varied considerably with the species, as well as with the place of origin, i.e. the apical or basal turn (Table I and Figs. 1-5). Guinea pigs consistently yielded isolated outer hair cells of excellent morphology. In Fig. 1, the cytoplasm shows large clear areas and many organelles, predominantly mitochondria, are present in the subcuticular and infranuclear portions of the cell. This distribution corresponds to that seen at the electron microscopic level. There is also a row of organelles, possibly mitochondria, located along the central axis of the cell. Frequently, as in this figure, stereocilia were seen projecting from the cuticular plate. Portions of a Deiters' cell (cup) often adhered to the base of the cell.

Chinchilla also consistently yielded cells that 

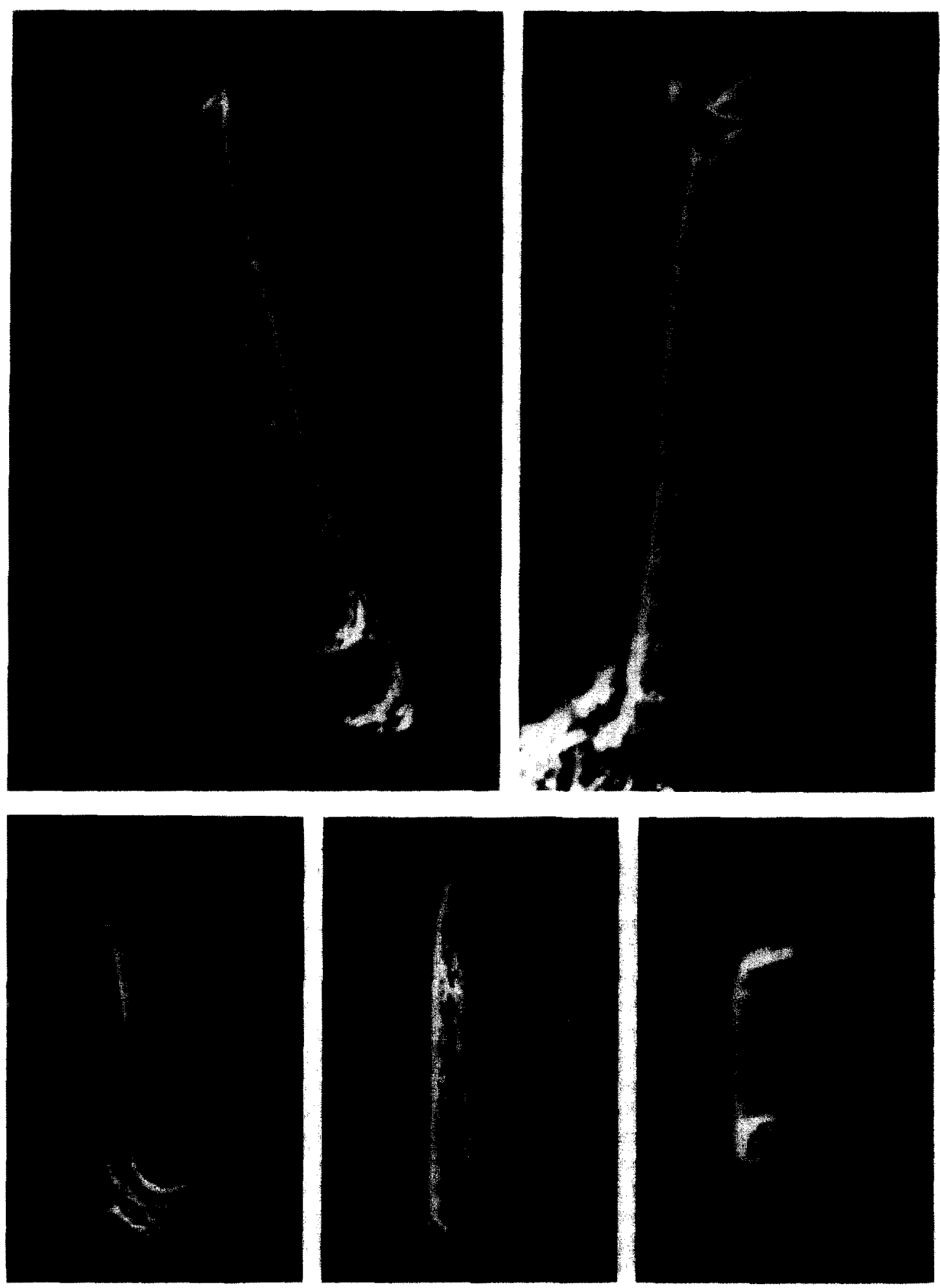

Figs. 1-5. Outer hair cells from different species. All hair cells were isolated from the apical tum of the cochlea as described in Methods and photographed under differential interference contrast optics. (Figs. 1 and 3 under $100 \times$ oil immersion). Calibration bar equals $10 \mu \mathrm{m}$. Fig. 1. Guinea pig. Fig. 2. Chinchilla. Fig. 3. Rat. Fig. 4. Gerbil. Fig. 5. Mouse. 
met the criteria of good morphological quality (Fig. 2). The position in which this chinchilla outer hair cell was photographed allows visualization of the region of the 'fonticulus', the apical portion of the cell which is not covered by the cuticular plate (Hawkins, 1976). The nucleus is in its normal position near the base of the cell. The row of organelles along the midline of the cell body are probably mitochondria associated with the subsurface cisternae. Part of a Deiters' cell and possibly afferent nerve endings are attached at the basal end, a frequent observation in hair cells from the chinchilla. This may be a property of collagenase-dissociated preparations since it does not seem to be observed after different enzymatic treatments (Lim and Flock, 1985).

\section{Dimensions}

The dimensions of isolated outer hair cells varied both between species and between base and apex (Iable II). There was a more than three-fold difference in average length between the largest (guinea pig, $74 \mu \mathrm{m}$ ) and the smallest cells (mouse, $22 \mu \mathrm{m}$ ) while the differences in diameter were less ( $<1.5$-fold). As a consequence, cell volumes differed more than five-fold. Apical hair cells were always considerably longer than basal cells while the diameter remained constant along the cochlea.

While the dimensions of isolated live outer hair cells are not explicitly stated in most of the previous studies, they can largely be extracted from the micrographs provided. There is excellent agreement between the size of apical cells reported here $(74.4 \pm 6.1 \mu \mathrm{m})$ and those in the very early studies (Katsuki and Covell, 1953; Goldstein and Mizukoshi, 1967) as well as Thalmann et al. (1972) quantitative data of 57-82 $\mu \mathrm{m}$ length depending on the row and $8.8 \mu \mathrm{m}$ diameter. Cells isolated by Zenner range from 60 to $80 \mu \mathrm{m}$ (Zenner and Schacht, 1986) *. Brownell shows hair cells of 37 , 62 (Brownell et al., 1985) and $52 \mu \mathrm{m}$ (Brownell, 1984) and these may be derived from different turns of the cochlea. The length of the chinchilla apical hair cell of about $60 \mu \mathrm{m}$ shown by Lim and

\footnotetext{
* A previously reported value of $36 \mu \mathrm{m}$ (Zenner et al. 1985b) for apical hair cells was corrected to $72 \mu \mathrm{m}$ after recalibration of the instruments (Zenner, pers. commun.).
}

Flock (1985) also falls in the range observed by us $(60.3 \pm 4.1 \mu \mathrm{m})$.

Base-to-apex gradients and species differences of the length of outer hair cells have also been well established through observations of fixed cochlear tissue (Retzius, 1884; Held, 1926; Spoendlin, 1966; Smith, 1968; Bohne and Carr, 1985). Particularly interesting is a comparison of our data with those of Hawkins (1965) who reported outer hair cells from the guinea pig to be $25 \mu \mathrm{m}$ long in the basal turn, $65 \mu \mathrm{m}$ long in the apex (third row; $45 \mu \mathrm{m}$ in the first row) and $7.5-8.0 \mu \mathrm{m}$ wide throughout the cochlea.

\section{Degeneration}

When viable hair cells were isolated from any species, their survival time as judged by the morphological criteria ranged from less than $1 \mathrm{~h}$ to 3-4 h. Hair cells which became attached to the bottom of the Petri dish survived better than their free-floating counterparts. A decisive factor in survival appeared to be mechanical trauma. Every manipulation of hair cells such as their transfer into a new solution, carefully executed with micropipettes, inflicted losses. If a cell was mechanically damaged a protrusion might appear anywhere along the membrane, although such injuries seemed more frequent at the extremes of the cell. The extruded cytosol contained particles exhibiting Brownian motion, but if the leak was small the cytosol would assume a gel-like appearance and the leak would be sealed within minutes. This often occurred without displacing the nucleus or the mitochondria or changing the general structure of the cytoplasm. If a protrusion is seen it should be assumed, however, that the cell has lost some of its integrity, even though it has maintained its normal shape and appearance. It would be interesting to determine whether mechanical stress to hair cells in vivo (e.g., in noise trauma) similarly leads to loss of cytoplasm. The mechanical trauma of the isolation procedure may also injure the stereocilia without apparent consequence for the viability of the cell body. This is suggested by Fig. 1,5 and $7 \mathrm{~A}$ but a precise assessment of stereociliar damage is not possible at the light microscopic level.

Two typical degeneration patterns observed in the absence of obvious mechanical injury (Figs. 

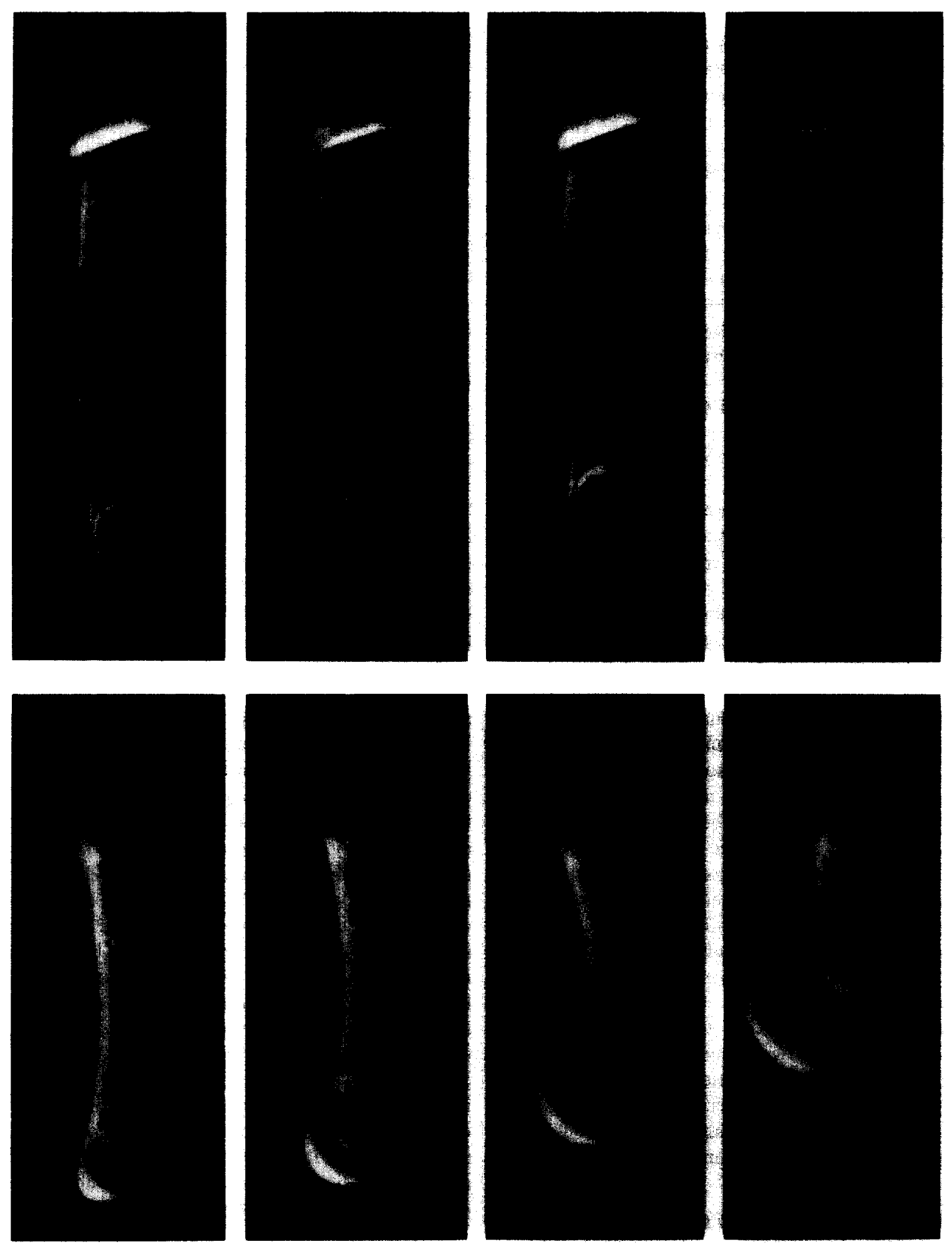
TABLE II

\section{DIMENSIONS OF ISOLATED OUTER HAIR CELLS}

\begin{tabular}{lllll}
\hline Species & & $\begin{array}{l}\text { Length } \\
(\mu \mathrm{m})\end{array}$ & $\begin{array}{l}\text { Diameter } \\
(\mu \mathrm{m})\end{array}$ & $\begin{array}{l}\text { Volume } \\
(\mathrm{pl})\end{array}$ \\
\hline Guinea pig (apex) & $74.4 \pm 6.1$ & $8.5 \pm 0.4$ & $4.3 \pm 0.5$ \\
(base) & $27.6 \pm 1.3$ & $8.6 \pm 0.1$ & $1.6 \pm 0.1$ \\
Chinchilla (apex) & $60.3 \pm 4.1$ & $10.2 \pm 0.7$ & $5.0 \pm 0.5$ \\
Mouse $\quad$ (apex) & $21.9 \pm 2.2$ & $7.1 \pm 0.8$ & $0.9 \pm 0.3$ \\
Rat & (apex) & $31.1 \pm 3.9$ & $9.1 \pm 0.7$ & $2.1 \pm 0.5$ \\
Gerbil & (apex) & $40.5 \pm 4.5$ & $9.4 \pm 0.2$ & $2.7 \pm 0.3$ \\
\hline
\end{tabular}

Measurements were taken from photographs of six to twelve viable hair cells derived from several different preparations. Volumes are calculated assuming a cylindrical shape. Numbers are means \pm S.D.

$6,7)$ were swelling at one location along the cell body or increasing granulation of the cytoplasm with eventual destruction of the cell. It should be noted that these degenerations occurred in isotonic media and thus do not represent damage due to osmotic influences. The ballooning was frequently seen at the base. This could signify a structural weakness since the apical part of the cell appeared rather resistant to such swelling. On the other hand, it may indicate that the base is subjected to more mechanical stress during the dissection. It is particularly noteworthy that both patterns resulted in a reduction of the size of the dying hair cell. This seems important in regard to studies of motile hair cell responses which rely on the demonstration of stimulus-induced length changes. Since noxious stimuli induced a slow shortening it is imperative that in physiological experiments the reversibility of the observed phenomenon be demonstrated, i.e. a return of the hair cell to its original morphological and physiological condition upon withdrawal of the stimulus
(Brownell, 1984; Brownell et al., 1985; Zenner et al. 1985b).

Another question that arises is to what extent the morphological degeneration of the hair cell affects cellular reactions. This may have to be established for each individual case, as physiological and biochemical mechanisms of different cellular organelles may have a varying susceptibility to degeneration. Responses to electrical stimuli (Brownell et al., 1985) as well as cytochemical reactions (Flock et al., 1986) have been demonstrated in cells that appear degenerating by the morphological criteria spelled out above. It would seem, however, that cells with good morphology and viability are more likely to yield experimental results unperturbed by artifacts.

\section{Conclusion}

Yield and viability of the isolated outer hair cells vary considerably not only with species but also with place of origin from the base or the apex of the cochlea. The resons for this variability elude us at the moment but may lie in difference in the anatomy and the nature of cell-to-cell connections. The fact that hair cells can be isolated from non-mammalian (Hudspeth, 1985) and outer hair cells from different mammalian vertebrates enables us to study their properties in terms of species comparisons and gain further insight into their anatomy, physiology, biochemistry and biomechanics.

The morphological criteria by which we have attempted to judge the quality of the isolated cells are only one consideration out of many but are easily recognized. Other criteria are the biopotentials of the cells where guidelines exist from in-vivo measurements. In the cochlea in situ, median resting membrane potentials of $-70 \mathrm{mV}$ are measured in outer hair cells in the third turn (Dallos et

Fig. 6, 7. Degeneration patterns of guinea pig hair cells. Cells were isolated as described in Methods and maintained in isotonic media.

Fig. 6. A normal-appearing hair cell (a, 15 min post mortem) has lost little if any of its integrity after 35 min but begins to shorten (b). Increased granulation and shortening is evident after $45 \mathrm{~min}$ (c) followed by disintegration of the basal part of the cell after 60 $\min (d)$.

Fig. 7. A normal-appearing hair cell $27 \mathrm{~min}$ after its isolation (a). At $89 \mathrm{~min}$ swelling is evident at its basal end (b). The swelling increases as the nucleus moves upward and the cell shrinks further after $100 \mathrm{~min}$ (c) and $140 \mathrm{~min}$ (d). 
al., 1982) and -30 to $-45 \mathrm{mV}$ in the basal turn (Russell and Sellick, 1978). Potentials of isolated outer hair cells have been reported as high as -6 to $-12 \mathrm{mV}$ (Brownell et al., 1985) and as low as $-70 \mathrm{mV}$ (Gitter et al., 1986; Zenner et al., 1985a). As hair cells degenerate in vitro their intracellular potential approaches $0 \mathrm{mV}$ (Brownell et al., 1985; Zenner et al., 1985a). This is accompanied by a loss of birefringence, a property of living cells obscrvablc with interference optics. Biochemical, immunological and functional integrity will be more difficult to establish as new definitions and knowledge of the selected parameters in vivo will be required. It may be helpful to correlate such additional criteria with the more directly accessible morphology of the cells.

\section{Acknowledgements}

The authors wish to express their gratitude to Dr. H.P. Zenner for introducing them to the isolation technique and to Dr. Richard Altschuler for helpful discussions and critique. This research was supported by a grant from the Deafness Research Foundation, NIH Program project grant NS05785, and a grant from the Biomedical Research Council, the University of Michigan.

\section{References}

Bohne, B.A. and Carr, C.D. (1985) Morphometric analysis of hair cells in the chinchilla cochlea. J. Acoust. Soc. Am. 77 , 153-158.

Brownell, W.E. (1984) Microscopic observations of cochlear hair cell motility. Scanning Electron Microsc. III, 1401-1406.

Brownell, W.E., Bader, C.R. Bertrand, D. and de Ribeaupierre, Y. (1985) Evoked mechanical responses of isolated cochlear outer hair cells. Science 227, $194 \cdots 196$.

Dallos, P., Santos-Sacchi, J. and Flock, A. (1982) Intracellular recordings from cochlear outer hair cells. Science 218 , 582-584.

Flock, A., Flock, B. and Ulfendahl, M. (1986) Mechanisms of movement in outer hair cells and possible structural basis. Arch. Otol Rhinol Laryngol. 243, 83-90.

Gitter, A.H., Zenner, H.P. and Frömter, E. (1986) Membrane potential and ion channels in isolated out hair cells of guinea pig cochlea. ORL $48,68-75$.

Goldstein, A.J. and Mizukoshi, O., (1967) Separation of the organ of Corti into its component cells. Ann. Otol. Rhinol. Laryngol. 76, 414-426.

Hawkins, J.E., jr. (1965) Cytoarchitectural basis of the cochlear transducer. Cold Spring Harbor Symp. 30, 147-157.

Hawkins, J.E., jr. (1976) Drug otoxicity. In: Handbook of Sensory Physiology, Vol. 3, pp. 707-748. Editors: W.D. Keidel and W.D. Neff. Springer-Verlag, Berlin.

Held, H. (1926) Die Cochlea der Säuger und der Vögel, ihre Entwicklung und ihr Bau. In: Handbuch der normalen und pathologischen Physiologie, vol. II, pp. 467-534. Editor: A Bethe. Springer-Verlag, Berlin.

Hudspeth, A.J. (1985) The cellular basis of hearing: The biophysics of hair cells. Science $230,745-752$.

Katsuki, Y. and Covell, W.P. (1953) The organ of Corti by phase contrast microscopy. Laryngoscope 63, 1-17.

Lim, D.J. and Flock, $\AA$. (1985) Ultrastructural morphology of cnzymc-dissociated cochlear sensory cells. Acta OtoLaryngol (Stockh.) 99, 478-492.

Neely, S.T. and Kim, D.O. (1986) A model for active elements in cochlear biomechanics. J. Acoust. Soc. Am. 79, 1472-1480.

Retzius, G. (1884) Das Gehörorgan der Wirbeltiere, II. Das Gehörorgan der Reptilien, der Vögel und der Säugetiere. Samson \& Wallin, Stockholm, Sweden.

Russell. I.J. and Sellick, P.M. (1978) Intracellular studies of hair cells in the mammalian cochlea. J. Physiol. 284, $261-290$.

Schacht, J. and Zenner, H.P. (1986) The phosphoinositide cascade in isolated outer hair cells: Possible role as second messenger for motile responses. Hear. Res. 22, 94.

Smith, C.A. (1968) Ultrastructure of the organ of Corti. Adv. Sci. 24, 419-433.

Spoendlin, H. (1966) The Organization of the Cochlear Receptor, p.7. Karger, Basel, Switzerland.

Thalmann, R., Thalmann, I. and Comegys, T.H. (1972) Quantitative cytochemistry of the organ of Corti. Dissection, weight determination and analysis of single outer hair cells. Laryngoscope 82, 2059-2078.

Zenner, H.P., Gitter A., Zimmermann, U., Schmitt, U. and E. Frömter (1985a) Die isolierte, lebende Haarzelle - Ein neues Modell zur Untersuchung der Hörfunktion. Laryngol. Rhinol. Otol, 64, 642-648.

Zenner, H.P., Zimmermann, U. and Schmitt, U. (1985b) Reversible contraction of mammalian cochlear hair cells. Hear. Res. 18, 127-133.

Zenner, H.P. and Schacht, J. (1986) Hörverlust durch Aminoglykosid Antibiotika: Angriff am Membranbaustein $\mathrm{PIP}_{2}$ in äusseren Haarzellen als Wirkungsmechanismus. HNO $34,417-423$. 